\title{
Low Energy Electron-Excited Nanoscale Luminescence: A Tool to Detect Trap Activation by Ionizing Radiation
}

\author{
B. D. White, L. J. Brillson, S. C. Lee, D. M. Fleetwood, R. D. Schrimpf, S. T. Pantelides, Y.-M. Lee, and G. Lucovsky
}

\begin{abstract}
Ultra-thin $\mathrm{SiO}_{2} / \mathrm{Si}$ gate dielectric structures exposed to heavy X-ray irradiation exhibit optical emission characteristic of interface traps. Low energy electron-excited luminescence spectroscopy with nanometer-scale depth resolution yields a characteristic spectral energy and excitation depth dependence. Ultra-thin $(5 \mathrm{~nm})$ oxide films on Si substrates exposed to $10 \mathrm{keV}$, 7.6 $\mathrm{Mrad}\left(\mathrm{SiO}_{2}\right)$ [13.7 $\left.\mathrm{Mrad}(\mathrm{Si})\right] \mathrm{X}$-ray irradiation introduces trap densities on the order of $10^{11} \mathrm{~cm}^{-2} \mathrm{eV}^{-1}$, localized near the intimate $\mathrm{SiO}_{2}-\mathrm{Si}$ interface. This density is consistent with the trapped oxide and interface charge densities expected based on observed capacitance- voltages shifts of thicker oxides, their corresponding charge densities, and the proportionally smaller charge densities expected for the thinner oxide layers in this study.
\end{abstract}

\section{INTRODUCTION}

A S MICROELECTRONIC device dimensions are scaled into the deep sub-micron regime, there must be corresponding decreases in the oxide-equivalent thickness of gate dielectrics. In order to avoid the charge tunneling associated with such thin layers, materials with higher dielectric constant $K$ are needed to maintain gate capacitance without further reduction in thickness. In addition, ultra-thin $\mathrm{Si}_{-} \mathrm{SiO}_{2}$ interfaces are needed that form a low interface trap density substrate for these high- $K$ dielectrics. Control of the chemical bonding and defect states in the immediate vicinity of these interfaces includes an understanding of the effect that ionizing radiation has on such defects. As part of our effort to understand the basic atomic-scale mechanisms responsible for the radiation-induced degradation observed in microelectronics, we are using low energy electronexcited nanoscale-luminescence (LEEN) spectroscopy, a very low energy analogue of cathodoluminescence spectroscopy [1], [2]. This technique provides a spectrally-resolved measure of

Manuscript received July 24, 2000. This work was supported by the Air Force Office of Scientific Research (Physics and Electronics Directorate (AFOSR/NE) under MURI Grant F49620-99-1-0289.

B. D. White is with the Department of Electrical Engineering, Ohio State University, Columbus, OH 43210 USA (e-mail: whiteb@ee.eng.ohio-state.edu).

L. J. Brillson is with the Department of Electrical Engineering and the Department of Physics, Ohio State University, Columbus, OH 43210 USA (e-mail: brillson@ee.eng.ohio-state.edu).

S. C. Lee, D. M. Fleetwood, and R. D. Schrimpf are with the Department of Electrical and Computer Engineering, Vanderbilt University, Nashville, TN 37235 USA (e-mail: ron.schrimpf@ vanderbilt.edu).

S. T. Pantelides is with the Department of Physics and Astronomy, Vanderbilt University, Nashville, TN 37235 USA (e-mail: pantelides@vanderbilt.edu).

Y.-M. Lee and G. Lucovsky are with the Department of Physics, North Carolina State University, Raleigh, NC 27695 USA (e-mail: Gerry_Lucovsky@ncsu.edu).

Publisher Item Identifier S 0018-9499(00)11258-4. free carrier recombination, yielding determinations of defect energy levels and relative densities as a function of distance from interfaces on a scale of nanometers. LEEN also enables observation of electronic transitions involving deep traps within wide band gap insulators such as $\mathrm{SiO}_{2}$ [3]. Such observations are inaccessible by conventional optical techniques. Measurements are performed in ultrahigh vacuum (UHV) to eliminate contamination effects and control interface chemical properties, as measured by surface science techniques. The technique is sensitive to the deep level electronic properties of native defects, impurities, chemically-induced interface traps and interfacial compounds. The depth of free carrier excitation and recombination varies from nanometers to microns as the beam energy varies, thereby discriminating between contributions from different layers of a multi-layer interface [4].

\section{EXPERIMENTAL PROCEDURE}

The LEEN spectroscopy experiment consists of an electron gun that illuminates a specimen in ultrahigh vacuum (UHV) at glancing incidence $\left(45^{\circ}\right)$. Incident beam currents at $1-4 \mathrm{keV}$ are nominally $1 \mu \mathrm{A}$ or less. Excitation area is typically $\sim 1 \mathrm{~mm}^{2}$ or less. UHV conditions are desirable to avoid the deposition of carbon on the surface from decomposing air molecules. Such carbon deposits reduce the optical emission significantly. The impinging electron beam produces a cascade of secondary electrons whose penetration depends strongly upon the initial beam energy $E_{B}$. An extrapolated depth-dose curve provides a relation between $E_{\text {Beam }}$ and depth of maximum energy loss [4]. For energies of a few $\mathrm{keV}$ or less, such depths are in the low nanometer range [5]. Monte Carlo simulations [6] of the electron cascade process confirm such calculations. $\mathrm{A} \mathrm{CaF}_{2}$ collection lens within the chamber relays the light out of the chamber into a monochromator and one of several photodetectors that cover the near IR to UV range. Deflection plates modulate the electron beam so that a lock-in amplifier can filter out any unmodulated background noise. Further details are available in prior publications [5], [7]. Measurements of ultra-thin $\mathrm{SiO}_{2}$ on $\mathrm{Si}$ are particularly challenging not only because of the low film thickness, but also because the indirect gap $\mathrm{Si}$ and the amorphous $\mathrm{SiO}_{2}$ both have relatively weak optical emissions. Nevertheless, the LEEN technique's ability to excite primarily in the region of interest compensates for much of this deficiency. The $\mathrm{SiO}_{2} / \mathrm{Si}$ specimens consisted of a $10 \mathrm{Ohm}$-cm, B-doped p-type (100) Si substrate, an interfacial oxide layer $0.5-0.6 \mathrm{~nm}$ thick prepared by remote plasma assisted oxidation, followed 


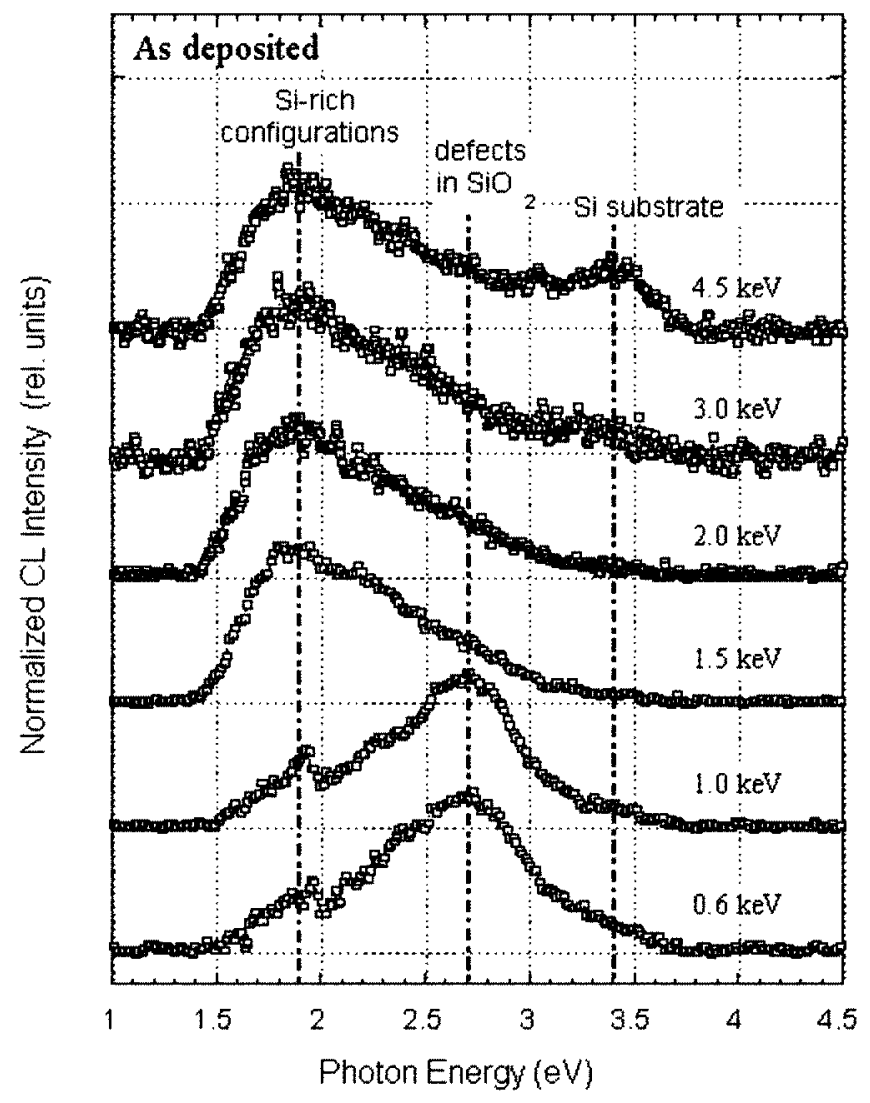

Fig. 1. Low energy electron-excited nanoscale spectroscopy of ultra-thin $\mathrm{SiO}_{2} / \mathrm{Si}$ interfaces as a function of increasing excitation energy and penetration depth. At low energies, excitation occurs primarily in the oxide and exhibits a pronounced peak at $2.7 \mathrm{eV}$. At higher energies a new feature appears at $1.9 \mathrm{eV}$ that is associated with the $\mathrm{Si}$ interface. Higher excitation energy produces emission at $3.4 \mathrm{eV}$ associated with the bulk Si [3]. All spectra are normalized to their largest peak feature.

by a $5.0 \mathrm{~nm}$ remote plasma enhanced chemical vapor deposition (RPECVD) carried out at $300^{\circ} \mathrm{C}$ [8]. The aim of this low thermal budget process developed by the North Carolina State University group is to minimize any chemical reactions or interdiffusion that would otherwise result from a high temperature oxidation process. X-ray irradiation was performed at Vanderbilt University with a $10 \mathrm{keV} \mathrm{X}$-ray source. Irradiated and un-irradiated specimens from the same wafer were then mailed to Ohio State University for the LEEN studies reported here.

\section{ULtRA-THIN $\mathrm{SiO}_{2} / \mathrm{Si}$ INTERFACES}

We have used LEEN spectroscopy to measure deep-level defects at $\mathrm{Si} / \mathrm{SiO}_{2}$ interfaces. These studies provide a clear determination of defect energies and relative densities within the ultra-thin $(5 \mathrm{~nm})$ oxide films on Si substrates, electronic states due to suboxide bonding with the monolayer transition region separating the $\mathrm{SiO}_{2}$ and $\mathrm{Si}$, as well as dangling bond defects at the interface on the Si side of the interface. Fig. 1 illustrates optical spectra acquired with a set of different incident $E_{B}$ from the $5 \mathrm{~nm}$-thick oxides on $\mathrm{Si}$ [3]. At low $E_{B}$, a prominent feature appears at $2.7 \mathrm{eV}$ along with a weak shoulder feature at $1.9 \mathrm{eV}$. Spectral features at these energies have been reported previously from cathodoluminescence spectroscopy measurements, albeit for thick film or bulk $\mathrm{SiO}_{2}$ [9]-[11]. With increasing $E_{B}$, the

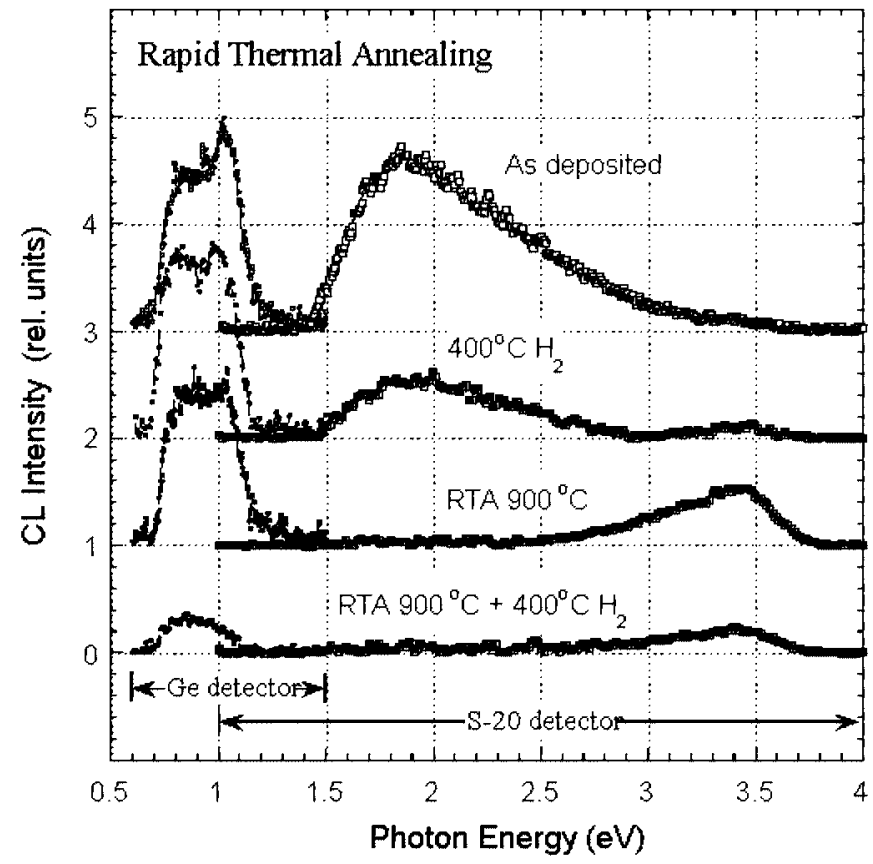

Fig. 2. Evolution of defect emission bands versus processing treatments, for the same $2.0 \mathrm{keV}$ LEEN excitation energy [3]. Spectral intensities between the two detectors are not normalized, but for each detector the relative intensities of the series of samples directly reflect the luminescence efficiency. A dramatic decrease in defect density is observed at $1.9 \mathrm{eV}$ upon annealing at $900^{\circ} \mathrm{C}$. Further processing reduces the trap-related features even further.

$2.7 \mathrm{eV}$ feature decreases and the $1.9 \mathrm{eV}$ increases as the penetration depth increases. These spectra reveal the depth variation of such defect features near interfaces. An additional feature at $3.4 \mathrm{eV}$ can be attributed to emission from the bulk substrate. The increase and decrease of these features are consistent with the calculated depths of excitation. Additional emissions (not shown) are detectable in the near IR, specifically a near band edge-related feature at $1.05 \mathrm{eV}$ and $0.8 \mathrm{eV}$. The latter " $P$ " center has been modeled based on electron paramagnetic resonance studies as a "dangling bond" defect in which an unpaired electron resides on a Si atom, backbonded to three other $\mathrm{Si}$ atoms at the $\mathrm{Si}-\mathrm{SiO}_{2}$ interface [12]. The broad feature at $1.9-2.0 \mathrm{eV}$ has been attributed to $a-\mathrm{SiO}_{x}$ bonding environments, interface microstructure, or associated point defects of the otherwise crystalline substrate [9]. Broad features peaking at $1.9 \mathrm{eV}$ or above are also reported for porous and hydrogenated amorphous Si films [13]. The $2.7 \mathrm{eV}$ feature has been reported previously in crystalline $\mathrm{SiO}_{2}$, amorphous $\mathrm{SiO}_{2}, \mathrm{SiO}_{x}$, and $\mathrm{SiO}_{x}$ at thermally-grown $\mathrm{SiO}_{2}-\mathrm{Si}$ interfaces. It is associated either with self-trapped excitons, two-fold coordinated $\mathrm{Si}$, or O vacancies. This $E^{\prime}$ center represents the most important trap center in silicon oxides and has been modeled to involve an unpaired electron localized on a $\mathrm{Si}$ atom back-bonded to three $\mathrm{O}$ atoms [12]. The $3.4 \mathrm{eV}$ emission corresponds to bulk Si transitions and provides a means to normalize the spectral intensities of the near- interface features [14]. Fig. 1 indicates that the $2.7 \mathrm{eV}$ and $1.9 \mathrm{eV}$ emissions originate from the oxide region within the film and near the interface respectively.

The LEEN spectroscopy technique can monitor the changes in defect properties with different gas and temperature treatments. Fig. 2 illustrates such changes with chemical treatments used to lower the interface trap density. A $400^{\circ} \mathrm{C} \mathrm{H}_{2}$ "post 

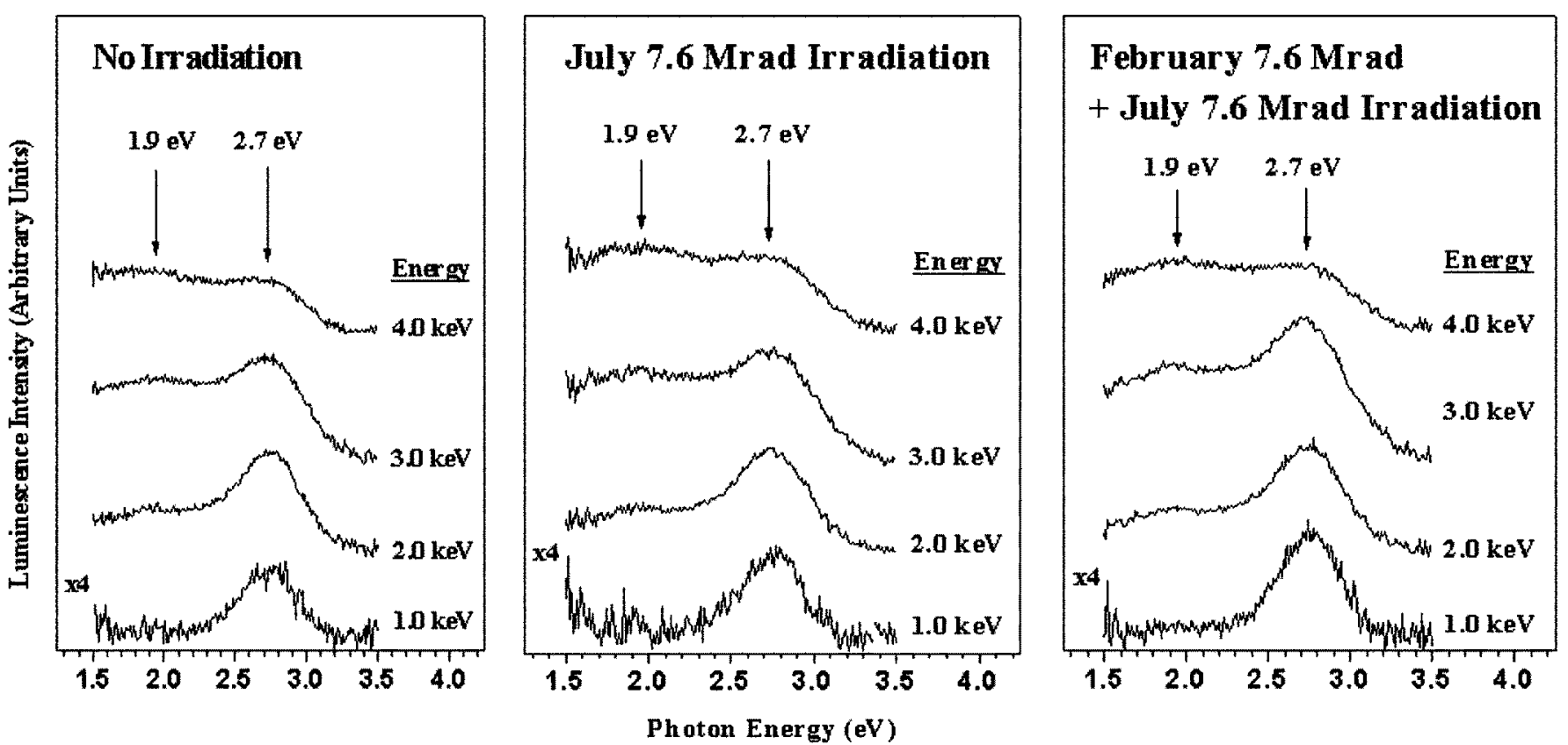

Fig. 3. Depth-resolved spectra of ultra-thin $\mathrm{SiO}_{2} / \mathrm{Si}$ interfaces with no irradiation (left), $10 \mathrm{keV} \mathrm{X}$-ray, $7.6 \mathrm{Mrad}\left(\mathrm{SiO}_{2}\right)$ irradiation (middle), and $10 \mathrm{keV} \mathrm{X-ray,}$ 15.2 $\mathrm{Mrad}\left(\mathrm{SiO}_{2}\right)$ irradiation (right). All three spectra exhibit peak features at $1.9 \mathrm{eV}$ and $2.7 \mathrm{eV}$ that reach maximum intensity below the free surface. A significant increase in $2.7 \mathrm{eV}$ peak height is apparent at $3 \mathrm{keV}$ for the highest dose. All spectra shown refer to a common intensity scale and directly reflect the relative luminescence efficiency.

metallization anneal" (PMA) in forming gas is intended to passivate $\mathrm{Si}$ dangling bonds. A $900^{\circ} \mathrm{C}$ rapid thermal anneal (RTA) acts to smooth the $\mathrm{SiO}_{2} / \mathrm{Si}$ interface and reduce suboxides. A subsequent PMA is intended to replace hydrogen and minimize Si dangling bonds after the RTA. The combination of $900^{\circ} \mathrm{C}$ plus $400^{\circ} \mathrm{C} \mathrm{H}_{2}$ anneal produces interfaces with low interface trap densities in the $10^{10}$ to $10^{11} \mathrm{~cm}^{-2}$ range for the low-energy CLS technique at the $\mathrm{Si} / \mathrm{SiO}_{2}$ interfaces [8]. The pronounced differences between spectra indicate that any electron beam-induced effects are relatively small in comparison with the process-induced features.

\section{IRRADiATED Ultra-THIN $\mathrm{SiO}_{2} / \mathrm{Si}$ INTERFACES}

Fig. 3 illustrates the effect of $10 \mathrm{keV}, 7.6 \mathrm{Mrad}\left(\mathrm{SiO}_{2}\right)$ [13.7 $\mathrm{Mrad}(\mathrm{Si})] \mathrm{X}$-ray irradiation on the $\mathrm{SiO}_{2}$ on Si near-interface region. These samples were grown and processed just as in case of those shown in Fig. 1 for the RTA $900^{\circ} \mathrm{C}+400^{\circ} \mathrm{C}$ $\mathrm{H}_{2}$ case. Fig. 3 illustrates depth-dependent LEEN spectra for specimens before and after irradiation. The increase in $2.7 \mathrm{eV}$ and $1.9 \mathrm{eV}$ emissions in all three spectral sets reaches a maximum between 2 and $3 \mathrm{keV}$, corresponding to the "buried," i.e., $\mathrm{Si} / \mathrm{SiO}_{2}$, interface region. No significant changes are evident after just the 7.6 $\mathrm{Mrad}\left(\mathrm{SiO}_{2}\right)$ irradiation. However, an additional 7.6 Mrad irradiation of this specimen produces a significant increase of the $2.7 \mathrm{eV}$ peak in the $3 \mathrm{keV}$ spectrum. In order to verify that such changes were not due to any artifacts, we performed another set of measurements on these specimens 9-11 days later. These appear in Fig. 4. The spectra shown in both Figs. 3 and 4 are shown with their absolute intensity, corrected only for the spectral response of the optical train. The multiple curves for the same energy in each panel of Fig. 4 illustrate variations $(\sim+8 \%)$ in spectra from point to point across the surface under identical conditions, separated only by millimeters or less. Each spectrum is acquired from a fresh spot in order to minimize any electron beam effects. Fig. 4 displays the same spectral features as in Fig. 3. However the relative increase in $2.7 \mathrm{eV}$ emission is now more apparent for the $15.2 \mathrm{Mrad}$ irradiation case than before, increasing relative to the unirradiated case by over $20 \%$ for both $3 \mathrm{keV}$ and $4 \mathrm{keV}$. The 15.2 Mrad panel also indicates somewhat sharper emission spectra at $1.9 \mathrm{eV}$ than in previous spectra, suggesting more than one origin for emission at these energies. Since this excitation occurs near the $\mathrm{SiO}_{2} / \mathrm{Si}$ interface in all these spectra, and few if any new point defects are expected to be created by $10 \mathrm{keV} \mathrm{X}$-ray irradiation in the bulk $\mathrm{Si}$, this result suggests that the emissions occur from traps localized near the $\mathrm{SiO}_{2} / \mathrm{Si}$ interface. Our initial conclusion is that the post-irradiation peak at $1.9 \mathrm{eV}$ is due to the same defects (presumably NBOHC or $P_{b}$ centers) as the as-processed interface traps in Fig. 2. This is consistent with a common origin for both irradiation and interface bonding defects, namely $\mathrm{Si}$ dangling bonds at the interface. These traps likely result from the migration of $\mathrm{H}$ to the interface and its subsequent reaction with $\mathrm{Si}-\mathrm{H}$ bonds [15]. The post-irradiation peak at $2.7 \mathrm{eV}$ is also consistent with a common origin for irradiation and interface bonding defects, possibly due to electromigration of mobile hydrogen-associated defects within the $\mathrm{SiO}_{2}$ film and across the Si interface [10]. While previous studies have reported optical emission from defects induced by X-rays in bulk amorphous $\mathrm{SiO}_{2}$ [16], the LEEN studies reported here appear to be the first to report such $\mathrm{X}$-ray-induced defect emission from $\mathrm{SiO}_{2}-\mathrm{Si}$ interfaces.

\section{ELECTRON BEAM EFFECTS}

We also performed studies of the electron beam itself on the ultra-thin $\mathrm{SiO}_{2} / \mathrm{Si}$ interfaces. Fig. 5 shows a series of spectra taken under typical voltage and power conditions as a function 

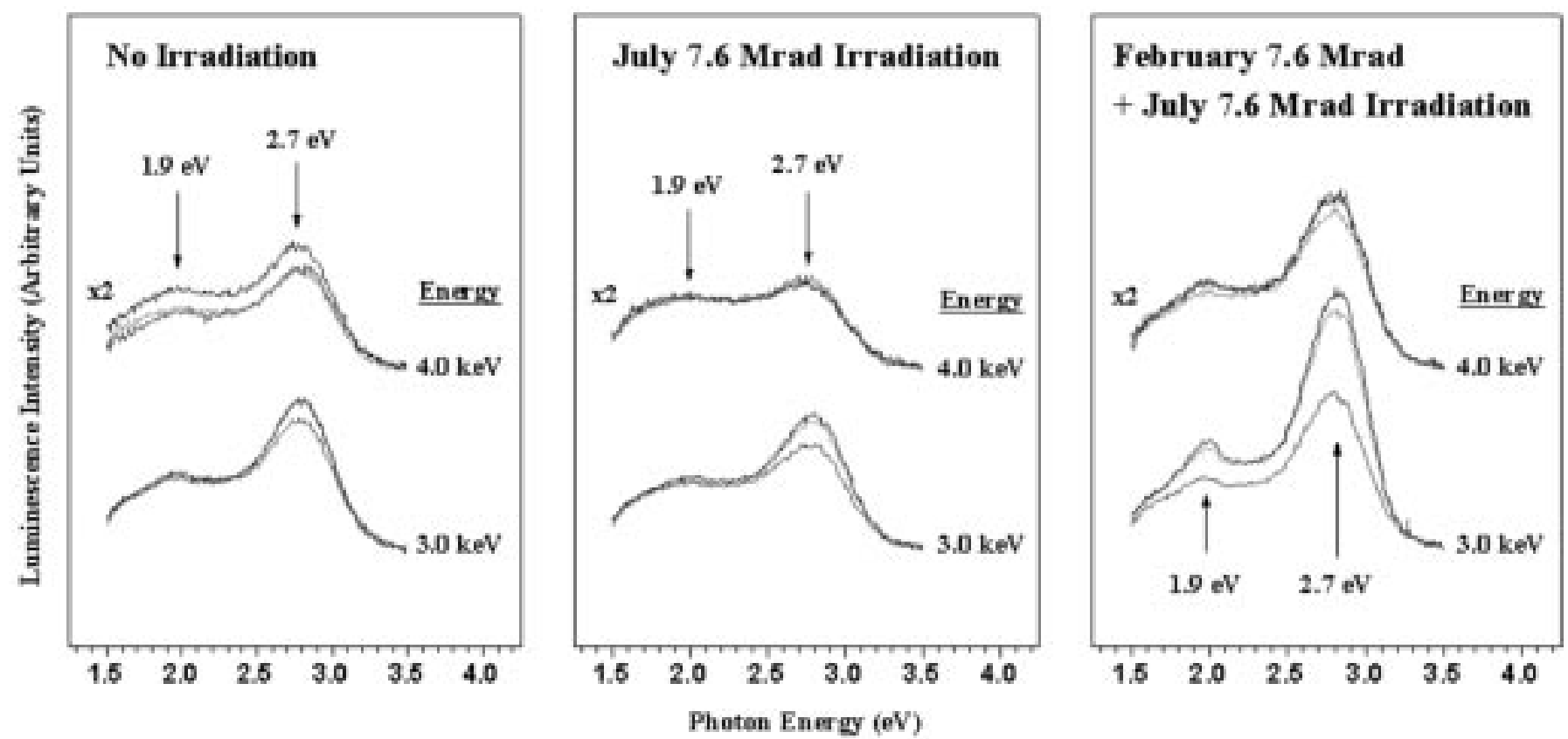

Fig. 4. Depth-resolved spectra of ultra-thin $\mathrm{SiO}_{2} / \mathrm{Si}$ interfaces 9-11 days after Fig. 3 measurements with no irradiation (left), $10 \mathrm{keV}$ X-ray, $7.6 \mathrm{Mrad}$ (SiO ${ }_{2}$ ) irradiation (middle), and $10 \mathrm{keV} \mathrm{X-ray,} 15.2 \mathrm{Mrad}\left(\mathrm{SiO}_{2}\right)$ irradiation (right). Different plots for the same energy indicate variations from point to point across $\mathrm{SiO}_{2} / \mathrm{Si}$ free surface. All three sets of spectra exhibit peak features at $1.9 \mathrm{eV}$ and $2.7 \mathrm{eV}$. A clear increase in $2.7 \mathrm{eV}$ peak height is evident at $3 \mathrm{keV}$ for the highest dose. All spectra shown refer to a common intensity scale and directly reflect the relative luminescence efficiency.

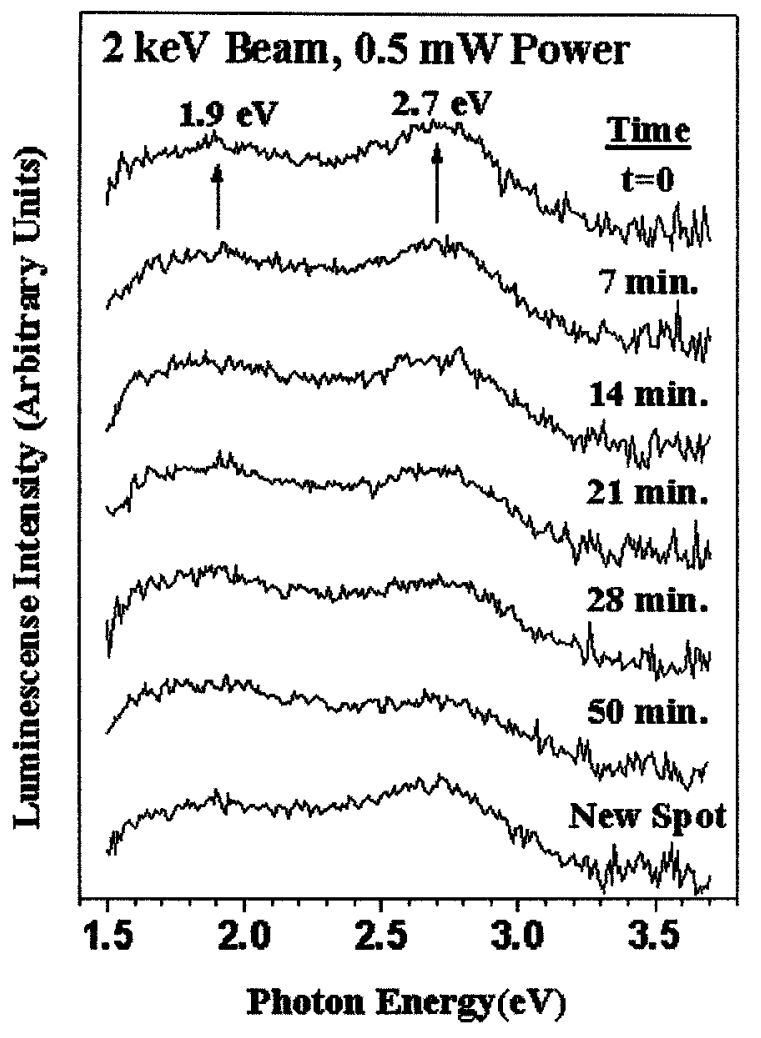

Fig. 5. Effect of electron beam exposure on the LEEN spectra. Individual 7 minute scans at $2 \mathrm{keV}$ and $0.5 \mathrm{~mW}$ power introduce no new features and less than a $10 \%$ decrease in the $2.7 \mathrm{eV}$ relative to $1.9 \mathrm{eV}$ feature heights. All spectra refer to a common scale and directly reflect the photoluminescence efficiency.

of time with the beam focused on the same specimen area. No new spectral features are produced by the electron beam. This figure also shows that the spectral features change only slowly with time compared with an individual beam scan of $7 \mathrm{~min}$. To emphasize that a change has indeed occurred, however, the spectrum for a new spot taken directly following the 50 minute spectrum is shown for contrast. Overall, the $2.7 \mathrm{eV}$ peak intensity decreases by $\sim 10 \%$ relative to the $1.9 \mathrm{eV}$ feature over the span of a single scan. It is important to note that this decrease is opposite to the effect we observe with $\mathrm{X}$-ray irradiation, i.e., the $2.7 \mathrm{eV} / 1.9 \mathrm{eV}$ ratio increases with $\mathrm{X}$-ray irradiation in these samples. Hence, we conclude that electron beam damage does not play a significant role in the previous experiments.

\section{DISCUSSION: OVERALl EFFECT OF X-RAY IRRADIATION}

$\mathrm{X}$-ray irradiation produces a relatively small but significant increase of trap density in the ultra-thin $\mathrm{SiO}_{2} / \mathrm{Si}$ specimens. Trap emissions are relatively low both before and after irradiation for the specimens grown by the RPECVD low thermal budget process. Since much larger emissions are observed for specimens before processing, irradiation appears to introduce only small changes of interface traps, on the order of $10^{11} \mathrm{~cm}^{-2} \mathrm{eV}^{-1}$. This density is consistent with the trapped oxide and interface charge densities expected based on observed capacitance-voltage shifts of thicker oxides, their corresponding charge densities, and the proportionally smaller charge densities expected for the thinner oxide layers [17]. While limited to detecting trap densities at or above this limit for ultrathin $\mathrm{SiO}_{2}$ on $\mathrm{Si}$, the LEEN technique appears well-suited to observe energies and depth variations of traps activated by X-ray irradiation, especially at high dose levels. For interfaces involving direct gap semiconductors, even higher detection levels are achievable [5]-[7], [18]. 


\section{CONCLUSION}

We have used low energy electron-excited nanoscale luminescence spectroscopy to detect optical emission from defects induced by X-ray irradiation. Further, the depth-dependence of the LEEN spectroscopy technique emphasizes the nearinterface nature of the defects and the potential role of electron-hole pairs generated within the Si substrate in generating such defects. The relatively small changes in trap features with irradiation indicate that the ultra-thin dimensions of the gate oxide minimize the creation of new oxide traps induced by X-rays. In general, the LEEN technique can probe such interfaces quite efficiently and is a promising method for use in studying the microstructural defects that lead to radiation damage in microelectronic materials.

\section{ACKNOWLEDGMENT}

Conversations with Dr. A. P. Young at Anadigics, Inc. are gratefully acknowledged.

\section{REFERENCES}

[1] L. J. Brillson, H. W. Richter, M. L. Slade, B. A. Weinstein, and Y. Shapira, "Cathodoluminesence spectroscopy studies of laser-annealed metal-semiconductor interfaces," J. Vac. Sci. Technol., vol. A3, no. 3, pp. 1011-1015, May/June 1995.

[2] L. J. Brillson and R. E. Viturro, "Low energy cathodoluminescence spectroscopy of semiconductor interfaces," Scanning Microsc., vol. 2, no. 2, pp. 789-799, 1998

[3] J. Schäfer, A. P. Young, L. J. Brillson, H. Niimi, and G. Lucovsky, "Depth-dependent spectroscopy defect characterization of the interface between plasma-deposited $\mathrm{SiO}_{2}$ and silicon," Appl. Phys. Lett., vol. 73, no. 6, pp. 791-793, Aug. 1998

[4] T. E. Everhart and P. H. Hoff, "Determination of kilovolt electron energy sissipation vs. penetration distance in solid materials," J. Appl. Phys., vol. 42, no. 13, pp. 5837-5846, Dec. 1971.
[5] L. J. Brillson, T. M. Levin, G. H. Jessen, and F. A. Ponce, "Localized states at InGaN/GaN quantum well interfaces," Appl. Phys. Lett., vol. 75, no. 24, pp. 3835-3837, Dec. 1999.

[6] P. Hovington, D. Drouin, and R. Gauvin, "CASINO: A new Monte Carlo code in C language for electron beam interactions-Part I: Description of the program," Scanning, vol. 19, pp. 1-14, 1997.

[7] T. M. Levin, G. H. Jessen, F. A. Ponce, and L. J. Brillson, "Depth-resolved electron-excited nanoscale-luminescence spectroscopy studies of defects near GaN/InGaN/GaN quantum wells," J. Vac. Sci. Technol., vol. B17, no. 6, Nov./Dec. 1999.

[8] D. R. Lee, C. G. Parker, J. Hauser, and G. Lucovsky, "Reliability of nitrided $\mathrm{Si}-\mathrm{SiO}_{2}$ interfaces formed by a new, low-temperature, remoteplasma process," J. Vac. Sci. Technol., vol. B13, no. 4, pp. 1788-1793, Jul./Aug. 1995

[9] M. A. Stevens Kalceff and M. R. Phillips, "Cathodoluminescence microcharacterization of the defect structure of quartz," Phys. Rev., vol. 52, no. 5, pp. 3122-3134, August 1995.

[10] M. A. Stevens Kalceff, G. J. Thorogood, and K. T. Short, "Charge trapping and defect segregation in quartz," J. Appl. Phys., vol. 86, no. 1, pp. 1-3, July 1999.

[11] S. W. McKnight and E. D. Palik, "Cathodoluminescence of $\mathrm{SiO}_{2}$ films," J. Non-Cryst. Sol., vol. 40, pp. 595-603, 1980.

[12] P. M. Lenahan and J. F. Conley Jr., "What can electron paramagnetic resonance tell us about the $\mathrm{Si} / \mathrm{SiO} 2$ system?," J. Vac. Sci. Technol., vol. B16, no. 4, pp. 2134-2153, July/August 1998.

[13] L. Canham, "Progress toward crystalline-silicon based light-emitting diodes," Mater. Res. Bull., vol. 18, no. 7, pp. 22-28, July 1993.

[14] H. R. Phillip and E. R. Taft, Phys. Rev., vol. 120, p. 556, 1960.

[15] S. T. Pantelides, S. N. Rashkeev, R. Buczko, D. M. Fleetwood, and R. D. Schrimpf, "Reactions of hydrogen with $\mathrm{Si}-\mathrm{SiO}_{2}$ interfaces," IEEE Trans. Nucl. Sci., vol. 47, Dec. 2000, to be published.

[16] L. N. Skuja, A. R. Silin, and A. G. Boganov, "On the nature of the 1.9 eV luminescence centers in amorphous $\mathrm{SiO}_{2}$," J. Non-Cryst. Solids, vol. 63, pp. 431-436, 1984.

[17] D. L. Griscom, "Optical properties and structure of defects in silica glass," J. Ceramic Soc. Jpn., vol. 99, no. 10, pp. 923-942, Oct. 1991.

[18] D. M. Fleetwood, D. E. Beutler, L. J. Lorence Jr., D. B. Brown, B. L. Draper, L. C. Riewe, H. B. Rosenstock, and D. P. Knott, "Comparison of enhanced device response and predicted X-ray dose enhancement effects on MOS oxides," IEEE Trans. Nuc. Sci., vol. 35, no. 6, pp. 1265-1271, Dec. 1988.

[19] A. P. Young and L. J. Brillson, "Luminescence spectroscopy of GaN in the high-temperature regime from room temperature to $900^{\circ} \mathrm{C}, " \mathrm{Appl}$. Phys. Lett., vol. 77, no. 5, pp. 699-701, July 2000. 